Goldschmidt 2021 Abstract

https://doi.org/10.7185/gold2021.6732

\section{Protracted oxygenation in the Paleoproterozoic did not result in proliferation of mitochondrial organisms}

\author{
KAAREL MÄND ${ }^{1}$, NOAH J. PLANAVSKY ${ }^{2}$, SUSANNAH \\ PORTER $^{3}$, LESLIE JAMIE ROBBINS ${ }^{4}$, CHANGLE \\ WANG $^{5,6,7}$, TIMMU KREISTMANN $^{8}$, KÄRT PAISTE ${ }^{1}$, \\ PÄÄRN PAISTE ${ }^{9}$, YULIA DEINES ${ }^{10}$, KALLE KIRSIMÄE $^{1}$, \\ AIVO LEPLAND ${ }^{11}$ AND KURT KONHAUSER ${ }^{12}$ \\ ${ }^{1}$ University of Tartu \\ ${ }^{2}$ Yale University \\ ${ }^{3}$ University of California Santa Barbara \\ ${ }^{4}$ University of Regina \\ ${ }^{5}$ Institute of Geology and Geophysics, Chinese Academy of \\ Sciences \\ ${ }^{6}$ Institutions of Earth Science, Chinese Academy of Sciences \\ ${ }^{7}$ University of Chinese Academy of Sciences \\ ${ }^{8}$ Jacobs University \\ ${ }^{9}$ University of Tartu, \\ ${ }^{10}$ Karelian Research Centre \\ ${ }^{11}$ Geological Survey of Norway \\ ${ }^{12}$ University of Alberta \\ Presenting Author: kaarel.mand@ut.ee
}

The appearance of mitochondrial eukaryotes was one of the most consequential evolutionary events in Earth's history [1]. In modern eukaryotes the mitochondria are primarily oxygenconsuming organelles, and it is commonly proposed that their acquisition was triggered by the appearance of substantial levels of atmospheric oxygen following the Great Oxidation Event (GOE) $\sim 2.4$ billion years ago (Ga). It is difficult to test this assertion, however, as current proxy records for oxygen availability following the GOE offer only brief, and often contradictory, snapshots of Earth's redox state, making a comparison with the eukaryote fossil record difficult.

Here we report a chromium isotope record from a $>2400-\mathrm{m}-$ thick section of the Onega Basin sedimentary succession, NWRussia, which formed between $\sim 2.09-1.96 \mathrm{Ga}$. Chromium isotope ratios are anomalous (up to $+1.63 \%$ o $\delta^{53} \mathrm{Cr}$ ) throughout the succession, across several facies shifts, constituting the oldest substantially fractionated values reported to date. This attests to atmospheric oxygen levels that remained above $0.1 \%$ of the present level [2] throughout the entire, possibly $>100$-millionyear, depositional period.

This period is, therefore, a prime candidate for the timing of mitochondrial acquisition. However, paleontological work in the Onega Basin and in contemporaneous successions have yielded no widely accepted evidence for fossil eukaryotes [3]. The first recognizably eukaryotic fossils only appear $\sim 1.6 \mathrm{Ga}$ in diverse assemblages preserved on numerous continents. Importantly, this time period ( 1.9-1.4 Ga) contrasts heavily with the Onega times in that it lacks substantial and sustained chromium isotope fractionations, indicating much lower and more variable atmospheric oxygen levels.

Hence, even if mitochondrial acquisition took place between 2.1-1.9 Ga, the current absence of evidence for any key biotic events in this period suggests that it didn't lead to noticeable change in the size, complexity, or diversity of eukaryotes. Barring future finds in older rocks, the first appearance of likely eukaryote fossils in a period of extensive deoxygenation leads to the conclusion that while the GOE may have facilitated the emergence of eukaryotes, it did not drive it.

[1] Lane \& Martin (2010), Nature 467, 929-934.

[2] Planavsky. et al. (2014), Science 346, 635-638.

[3] Javaux \& Lepot (2018), Earth-Sci. Rev. 176, 68-86. 